\title{
HOW DISNEY SAVES ENERGY (Hint: It's Not Magic)
}

\author{
Paul J. Allen, P.E. \\ Walt Disney World
}

\section{ABSTRACT}

The Walt Disney World Resort near Orlando, Fla., is among the most highly visited destinations on earth. Its "campus" consists of 47 square miles containing hundreds of buildings that include world-class hotel and conference centers, theme parks and exotic ride adventures, and precisely controlled spaces for horticulture and animal care.

In addition to a Wall-Street eye on the bottom line, Walt Disney himself encoded the company's DNA with an ethic toward conserving natural resources and the environment that remains to this day as a program called Environmentality. Environmentality is a way of thinking, acting, and doing business in an environmentally conscientious way - from saving energy and water to reducing waste and other environmental impacts.

At Disney, energy management is a key to success. Air-conditioning, refrigeration, compressed air, and water-moving systems for buildings, rides, and transportation all run primarily on electricity and natural gas. To maximize energy conservation and efficiency while minimizing costs and environmental concerns, the Walt Disney World Resort has implemented a state-of-the-art energy management program (EMP) that can, and has served as a role model to owners and administrators of public and private facilities.

This paper describes the energy management program at the Walt Disney World Resort near Orlando and discusses its results in terms of energy and cost savings. Perhaps in doing so, other facility owners worldwide will develop their own energy management programs and cultivate the economic, energy, and environmental benefits enjoyed by Disney (1)(4)(6)(9)(10).

\section{THE ENERGY STAR FOUNDATION}

The cornerstone of the Disney EMP is its strong relationship with the U.S. Environmental Protection Agency (EPA) through the EPA Energy Star Buildings program, which has five main components:

- Building tune-up (recommissioning).

- Energy-efficient lighting (Green Lights).

- Load reductions.

- Fan-system upgrades.

- Heating-and-cooling-system upgrades. 
The relationship between the Walt Disney World Resort and the Energy Star Buildings program was established in 1996, when Disney implemented the EPA Green Lights program across 17 million sq ft of facilities. This was completed in 1998 and resulted in annual electrical savings of 46 million kwh. Also in 1998, the Walt Disney World Resort began the implementation of numerous other cost-effective energy-saving projects.

Disney's projects included:

- Optimizing compressed-air-system controls

- Upgrading hot-water-boiler controls

- Retrofitting variable-speed-drives into air, pumping, and chilled-water systems

- Retrofitting demand-controlled ventilation into convention-center spaces

- Upgrading and integrating energy-management-systems (EMS), including networking one EMS vendor's stand-alone EMS to centralized network-based servers.

- Installing utility-submetering systems in areas operated by non-Disney companies working in Disney facilities for utility cost recovery purposes.

In aggregate, the efforts Disney has undertaken since 1996 have resulted in a 53percent internal rate of return (IRR) and metered annual reductions of approximately 100 million kwh of electricity and 1 million therms of natural gas.

\section{THE DISNEY EMP FRAMEWORK}

Disney's multifaceted EMP has three main components: the energy management systems (EMS) that are installed in each building or facility; the Energy Information System (EIS), which is a suite of information technologies that works with the EMS to provide data and information to energy managers and other stakeholders; and Disney staff (called "cast members"), who collectively participate in the EMP. It's the combination of technology and people that makes Disney's EMP successful and sustainable.

\section{ENERGY MANAGEMENT SYSTEM}

\section{Overview}

The energy management systems (EMS) used at the Walt Disney World Resort are used to control energy consuming equipment - primarily for heating, ventilating and air conditioning (HVAC) equipment and lighting control. The parameters of greatest interest are temperature and humidity setpoints and equipment operating time schedules.

Over the years, Disney has installed a variety of Energy Management Systems from different vendors, which it continues to operate. One vendor's system controls more 
than 80 percent of the installed EMS base. This system was upgraded to a centralized server-based system connected to the corporate Ethernet-based intranet. This upgrade provided Disney's EMS with a standard and stable hardware and software platform along with the other benefits shown below:

- Review of EMS field panel programming and real-time operation can be made "globally" through any desktop PC on the corporate network.

- The EMS program and data is stored on network servers that are maintained by Disney's Information Services Team. Backups are made daily.

- Automatic reset of equipment time and setpoint schedules are made daily from a server-side control program.

- Data collection for both EMS point trends and utility meter data can be collected and used by the Energy Information System for quick and easy display.

- Maintenance and training of the EMS is simplified.

- Services contracts are minimized or eliminated.

- EMS spare parts inventory is minimized.

\section{Disney EMS Design Strategy}

Disney's approach to EMS is simple and straightforward. By standardizing on one manufacturer's EMS, Disney has achieved the following desirable results:

- Single-Seat User Interface

- Compatible with Existing EMS

- Easy-to-Use

- Easily expandable

- Competitive and Low-cost

- Owner Maintainable. No service contract required

Disney's EMS vendor's system uses a proprietary protocol, which is not "open". Standardizing on one EMS-vendor's system minimizes the importance of the EMS protocol used. Disney considers the ability to design, install, program, create graphics and continuously improve their EMS in-house the most important feature.

With one single-vendor EMS, this begs the question of how Disney keeps procurement competitive. Here's how: During a procurement effort, Disney will:

- Design the EMS controls as part of the construction documents. This includes details on EMS-panel wirelists, EMS communications interconnections, and EMS panel mounting details.

- Prescriptively specify every detail of the EMS (sensors, actuators, wire, etc.) so there is absolutely no doubt what will be installed and how it will be installed.

- Competitively bid the installation of the wire, conduit, sensors and actuators.

- Owner furnish the EMS panel and everything inside (EMS hardware, interface modules and power supply) 
During construction of the EMS, there are actually two contractors. The Controls Contractor scope of work is competitively bid and includes the installation of all the end devices and pulling all the control wires (properly labeled per the wirelist detail drawing) back into the EMS control panels. The EMS Contractor performs the wire termination, programming and startup of everything inside the EMS Panel. The EMS Contractor is very knowledgeable of how Disney's EMS Vendor's equipment is installed and configured.

The key to Disney's success is that it is in complete control of the process. The EMS Vendor is part of the process, not the master.

\section{ENERGY INFORMATION SYSTEM}

\section{Utility Reporting System}

The philosophy, "If you can measure it, you can manage it," is critical to a sustainable EMP. Measurement for management is the job of the EIS. The EIS is a suite of programs and computers that take data from the EMS and other data collection sources and churn it into actionable information for use by operators and managers. The EIS measures energy at the facility level and tracks the resulting energy conservation efforts over time.

Continuous feedback on utility performance pinpoints problems in the EMS that need attention. Such feedback also drives Disney's incentive program, which keeps people actively seeking to reduce consumption and expenses without creating new problems.

Disney created their own web-based EIS that uses an off-the shelf database management system to store the vast amount of energy data they collect $(5)(7)(8)$. The custom program, called the Utility Reporting System (URS), resides on a network web server. The URS gathers, stores, and processes monthly utility bill data and hourly meter data from a variety of data collection sources. The URS's reports are created in Web-accessible (HTML) formats and can be reached via the Disney intranet.

One popular feature of the URS is a "report-card" format for publishing utility data and historical information. The report card is distributed via e-mail on a monthly basis, with each message containing high-level (summary) information and hyperlinks allowing "point-and-click" access to greater detail. Some links are to graphs that compare current data to data from up to 12 previous months. Also, data can be filtered to compare one Disney area against others. For example, how is Epcot performing relative to Animal Kingdom? Such comparisons foster a healthy spirit of competition among area managers.

Specialized reports are used to monitor and report utility usage in areas operated by non-Disney companies working in Disney facilities, which helps to keep them aware of their usage rates. By measuring actual energy consumption instead of a square foot 
allocation, operating participants are motivated to manage their energy usage to keep their utility expenses low.

\section{Disney Goes to School}

The Walt Disney World Resort participated in a public/private effort to develop an energy information system, called Utility Report Cards (URC), to help Orange County Public Schools (OCPS) better manage energy costs. The URC program was based on the energy information system methods and techniques developed at the Walt Disney World Resort. The URC is a Web-based energy-information system that reports and graphs monthly utility data for schools.

Each month, a Web-based report is automatically generated and e-mailed to school principals and staff as encouragement to examine their school's electricity usage (energy efficiency) and to identify schools with high-energy consumption needing further investigation. The URC also is intended for teachers and students to use as an instructional tool to learn about school energy use as a complement to the energyeducation materials available through the U.S. Department of Energy's EnergySmart Schools program (ESS). To see how the URC operates, go to http://www.utilityreportcards.com and click on "URC Live."

The URC was created to help OCPS staff understand and, therefore, manage their utility consumption and associated costs. The URC allows school principals to become aware of how their school is performing relative to a projected benchmark and to other schools of similar design and capacity. Giving recognition to schools that improve performance from prior-year levels could create a spirit of competition with the opportunity to recognize success. Those schools identified as high-energy users become the focus of attention to determine the reasons for their consumption level and ultimately to decrease the energy used. All of this is done by using the monthly utility data that is provided electronically at minimal or no cost to the schools by the utilities.

\section{PEOPLE ARE THE REAL ENERGY STARS}

\section{Organization}

Conservation has always been one of Disney's core values. In a public-service announcement recorded while he was the honorary chairman of National Wildlife Week, Walt Disney defined "conservation" and thereby set a tone for Walt Disney's Environmentality ethic:

“You've probably heard people talk about conservation. Well, conservation isn't just the business of a few people. It's a matter that concerns all of us. It's a science whose principles are written in the oldest code in the world, the laws of nature. The natural resources of our vast continent are not inexhaustible. But if 
we will use our riches wisely, if we will protect our wildlife and preserve our lakes and streams, these things will last us for generations to come."

Disney's Environmentality Program provides the framework behind Disney's resource conservation efforts. Everyone has a role to play. There is a dedicated staff of energy conservation engineers and technicians who orchestrate the energy conservation efforts and keep the program moving forward by refining the EMS, EIS and other program components.

Management supports the EMP by promoting and encouraging energy savings efforts and authorizing budgets sufficient to get meaningful work done. New projects are considered based on their expected internal rate of return (IRR). There may also be other non-financial benefits that weigh in to the energy project funding decision.

Disney also recognizes that cast members need to be involved in the EMP to establish a facility-wide sense of ownership and accountability for energy usage. Through Disney's Environmental Circles of Excellence, Disney cultivates Environmentality instead of dictating it. These local teams meet monthly and work on various resource conservation projects in their respective park, resort or support area. Using the Environmentality motto, "Every little bit makes a BIG difference" lets cast members participate in identifying energy waste no matter how small the detail.

\section{Energy Star Tool Bag}

How Disney saves energy is not "magic". The Energy Star Tool Bag was created as a guide to help cast members look for energy waste.

\section{Overall Building}

1. Heating, Ventilating and Air Conditioning (HVAC).

- Turn off units during unoccupied hours.

- Adjust temperature and humidity setpoints to minimize unnecessary heating and cooling.

2. Turn off interior and exterior lighting when not required.

3. Perform walk-through's - look for energy waste

- Any exterior lighting on during the day?

- Note "too cold" or "too hot" areas.

- Note any areas that are "too humid"

- Close open doors during hot or cold weather

- Is all non-essential lighting turned off/dimmed down?

- Are there any PC's left on?

- Are there any decorative fountains on? 
- Can building facade or other decorative lighting be turned off?

4. Review utility metering reports and look for energy waste.

\section{$\underline{\text { In the Office }}$}

1. Turn your lights off when you leave your office or conference room.

2. Program your PC monitor, printer and copier to "go to sleep" during extended periods of non-activity

3. Turn your computer off completely when you leave to go home.

\section{$\underline{\text { In the Kitchen }}$}

1. Minimize Kitchen equipment pre-heat times.

2. Turn cooking equipment down or off during slow periods of the day

3. Eliminate water waste, report leaking faucets.

4. Turn off kitchen hoods after closing.

5. Turn off or reduce lighting levels in dining areas \& kitchen after closing.

6. Keep refrigerator/freezer doors closed. Install plastic strip doors on refrigerator/cooler doors.

\section{$\underline{\text { In Convention Areas }}$}

1. Turn off lighting and HVAC equipment during unoccupied hours.

\section{Swimming Pools}

1. Adjust pool water heating temperatures to minimize natural gas consumption during winter months.

\section{$\underline{\text { In Guest Rooms }}$}

1. Setback Guest Room Thermostat to low cool.

2. Close Drapes in Guest Rooms.

3. Keep sliding doors closed.

4. Turn off lights in Guest Rooms.

\section{Energy Star Team}

Cast members that participate in the Disney's EMP are part of the "Energy Star Team". The Energy Star Team meets on a monthly basis and is comprised of cast members from parks, resorts and support areas. The meetings provide a great opportunity to share and discuss best practices and learn of vendors energy-saving products. If one team member wants to try a technology in his or her area, the product is installed and metered to measure the results. If it works, it can be rolled out to the entire property. 
The Energy Star Team meetings also provide a good venue for providing on-going training to operators of the EMS and EIS.

The cast members that make up the Energy Star Team are typically from Maintenance or Operations. Since the cast members that participate do so in addition to their normal job responsibilities, the most successful team members are the ones that want to participate. While knowing some technical details of energy management is helpful, more important is the ability to get things accomplished by effective networking within their areas. The dedicated energy management staff can generally provide the technical skills training needed for the team.

\section{Utility Report Card}

The challenge for any large scale EMP is to sustain the process and to keep everyone focused on saving energy. Disney uses their monthly Utility Report Card as a scorecard on how each area is doing. By making the Utility Report Card easy to use and delivering it quickly and efficiently via email, management can easily determine how well their area is performing relative to other areas. Areas that have increased consumption are easily identified from the URC report. Management can question the increases and that is generally all that it takes to motivate those responsible individuals to take action. Knowing everyone is looking at the URC keeps the focus on finding new ways to saving energy.

\section{Energy Star Awards}

The Energy Star Awards program was developed to increase the awareness of energy usage among Disney management and cast members. It works by recognizing and rewarding successful energy conservation efforts and demonstrates that energy conservation can be simple and fun.

Because utility meter information is readily available in the URS, a report was developed to provide feedback on how well each area is doing relative to prior year usage. For example, Magic Kingdom, Epcot and Contemporary are all separately tracked and reported.

A spirit of competition is created by ranking each area based on percent change from the prior year. The areas with the greatest reductions rise to the top of the list. The awards recognize those areas that are at the top and identify those areas on the bottom as being in need of improvement.

Each year, a report is generated to show the award winners. Details on the award winners' accomplishments are highlighted in Disney's corporate Environmentality report, Enviroport. No cast member individually benefits financially from the EMP. Recognition for doing a good job has been the only incentive needed. 


\section{THE BUILDING TUNE-UP PROCESS}

\section{Overview}

The Building Tune-Up (BTU) (2) or re-commissioning (3) step in the Energy Star Buildings program has been very cost-effective for Disney. The BTU process concentrates on optimizing the operation of the EMS and generally results in a 5-20 percent reduction in utility usage in a very cost-effective manner. Disney's savings attributed to the BTU process have been approximately equal to the savings resulting from its Green Lights Program, but at a fraction of the cost (figure 1).

At the start of a BTU effort, teams are formed from the engineering and operations departments to review the building and EMS control devices, programming and settings. The BTU process typically results in the following:

- Reduced utility consumption by optimizing air conditioning and lighting time schedules and setpoints

- Improved EMS performance by improving energy management system programming \& documentation

- A list of corrective actions identified by monitoring HVAC system operations

- Measured utility savings using the URS

The BTU process is simple and can be started at anytime. The area Energy Star Team Member generally organizes the BTU team for his or her area. An energy management engineer facilitates BTU teams with support from facility-engineering and building operations and maintenance departments. Initially, 1-hr meetings are held once a week. This may not seem like much time, but a slow and steady pace is best for this type of work. Most of the detailed work is spent between the weekly meetings in the review and documentation of the EMS control sequences, setpoints, and time schedules. Each building and each HVAC system is evaluated one system at a time until all of the systems have been reviewed and everything is working properly.

\section{Computer Programs}

The key to a successful BTU program is to manage the details. To help with that effort, Disney uses several custom software tools that work together to keep EMS settings intact.

The Facility Time Schedule (FTS) program manages equipment time schedules and temperature setpoints in a central database. Because time schedules and setpoints can be changed from their optimal settings and not set back, the FTS was created to reset them automatically on a daily basis. 
The Building Tune-Up System (BTUS) is a Web-based program that allows users to view EMS control settings without accessing the EMS. Critical parameters of EMS operation are stored in a relational database. A Web-accessible program displays the information via a Web browser. The BTUS shows:

- HVAC equipment and the area serviced, including color-coded floor plans of the area serviced.

- Equipment time schedules and setpoints.

- Action items for follow-up repair for each HVAC system.

- Links to EMS trend graphs and historical data of utility-consumption.

The Energy Management Tune-Up System (ETS) is a web-based program that lets users search through their energy management systems for equipment not working properly. The ETS is actually two separate programs. The first program reads each EMS point and records those values in a central database. The data is recorded twice a day - during the daytime operational period and during after midnight closing period.

The second program provides the users with a web-based interface to scan though their area data to look for the following EMS problems:

- Chilled Water valves that are closed but the supply air temperature is $<60 \mathrm{~F}$ (Chilled water valves not closing).

- Fans that are commanded off but the fan status is on (Fan is not turning off).

- Temperature and humidity sensors out of range (sensors defective).

- Override forces on control points

\section{PROJECT SUPPORT}

New projects and renovations provide a great opportunity to incorporate energy saving products into the design. Even though the incremental cost to install an energy saving project would most likely be lowest if installed during a scheduled facility downtime or as part of new construction, the project budget might not be able to support the increased incremental cost. Estimating the potential internal rate of return (IIR) resulting from the expected annual cost savings helps justify increased project budget. A business case can be prepared that details the scope, shows alternatives, describes potential risks and rewards of the project. A strong business case and a high IRR will certainly help sell the project to management.

Replacement of Heating, Ventilating and Air Conditioning (HVAC) equipment is an opportune time to incorporate more efficient equipment and new energy management system controls. For example, with the Walt Disney World Resort's hot humid climate, the addition of a heat pipe wrapped around the cooling coil in a $100 \%$ makeup air unit provides an efficient method to control humidity while minimizing cooling and reheat energy costs (11). 


\section{CONCLUSION}

Environmentality is part of the way of life at the Walt Disney World Resort. Energy management programs are good for the environment and make good business sense.

The Disney EMP began by working with and learning from the well-established Energy Star Buildings program, which is available to everyone at http://www.energystar.gov.

Disney adopted Energy Star and then tailored it by integrating commercial energy management systems with a custom energy information system. This technology-based solution is used throughout the Disney World Resort organization by administrative managers, engineering, operations and maintenance staff, and cast members. This combination of people and technology has resulted in a sustainable energy management program at Walt Disney World. As the Walt Disney World Resort continues to expand, these programs will continue to play an important role in reducing energy costs in both new and existing facilities.

\section{REFERENCES}

1. How Disney Saves Energy and Operating Costs, Paul J. Allen, P.E., Heating/Piping/Air Conditioning (HPAC) Engineering, January 2005.

2. Continuous Commissioning ${ }^{\mathrm{SM}}$ in Energy Conservation Programs, W. Dan Turner, Ph.D., P.E., Energy Systems Lab, Texas A\&M University, Downloaded from http://esl.tamu.edu/cc on Dec. 20, 2004.

3. ENERGY STAR Buildings Upgrade Manual - Stage 2 Building Tune-Up, US EPA Office of Air and Radiation, 6202J EPA 430-B-97-024B, May 1998

4. Disney's "Environmentality Program", Paul J. Allen, Brett Rohring, Proceedings of the Energy 2003 Workshop and Exposition, August 17-20, 2003

5. Information Technology Basics for Energy Managers - How a Web-Based Energy Information System Works, Barney Capehart, Paul J. Allen, Klaus Pawlik, David Green, Proceedings of the 25th World Energy Engineering Congress October 9-11, 2002

6. Sustainable Energy Management - Walt Disney World's Approach, Paul J. Allen, Proceedings of the Energy 2002 Workshop and Exposition, June 2-5, 2002

7. Managing Energy Data Using an Intranet - Walt Disney World's Approach, Paul J. Allen, David C. Green, Proceedings of the Business Energy Solutions Expo November 28-28, 2001 
8. Measuring Utility Performance Through an Intranet-Based Utility Monitoring System, Paul J. Allen, Ed Godwin, Proceedings of the 23rd World Energy Engineering Congress October 25-27, 2000

9. Walt Disney World's Environmentality Program, Paul J. Allen, Bob Colburn, Proceedings of the Business Energy Solutions Expo December 1-2, 1999

10.Walt Disney World's Energy Management Program, Paul J. Allen, Ed Godwin, Proceedings of the Business Energy Solutions Expo December 9-10, 1998

11. Applications of Heat Pipes for HVAC Dehumidification at Walt Disney World, Paul J. Allen, Khanh Dinh, Proceedings of the 15th World Energy Engineering Congress October 27-30, 1992

\section{ABOUT THE AUTHOR}

Paul J. Allen, P.E. is the Chief Energy Management Engineer at Reedy Creek Energy Services (a division of the Walt Disney World Co.) and is responsible for the development and implementation of energy conservation projects throughout the Walt Disney World Resort. Paul is a graduate of the University of Miami (BS degrees in Physics and Civil Engineering) and the University of Florida (MS degrees in Civil Engineering and Industrial Engineering). Paul is also a registered Professional Engineer in the State of Florida. The Association of Energy Engineers (AEE) inducted Paul into the Energy Managers Hall of Fame in 2003. (paul.allen@disney.com) 


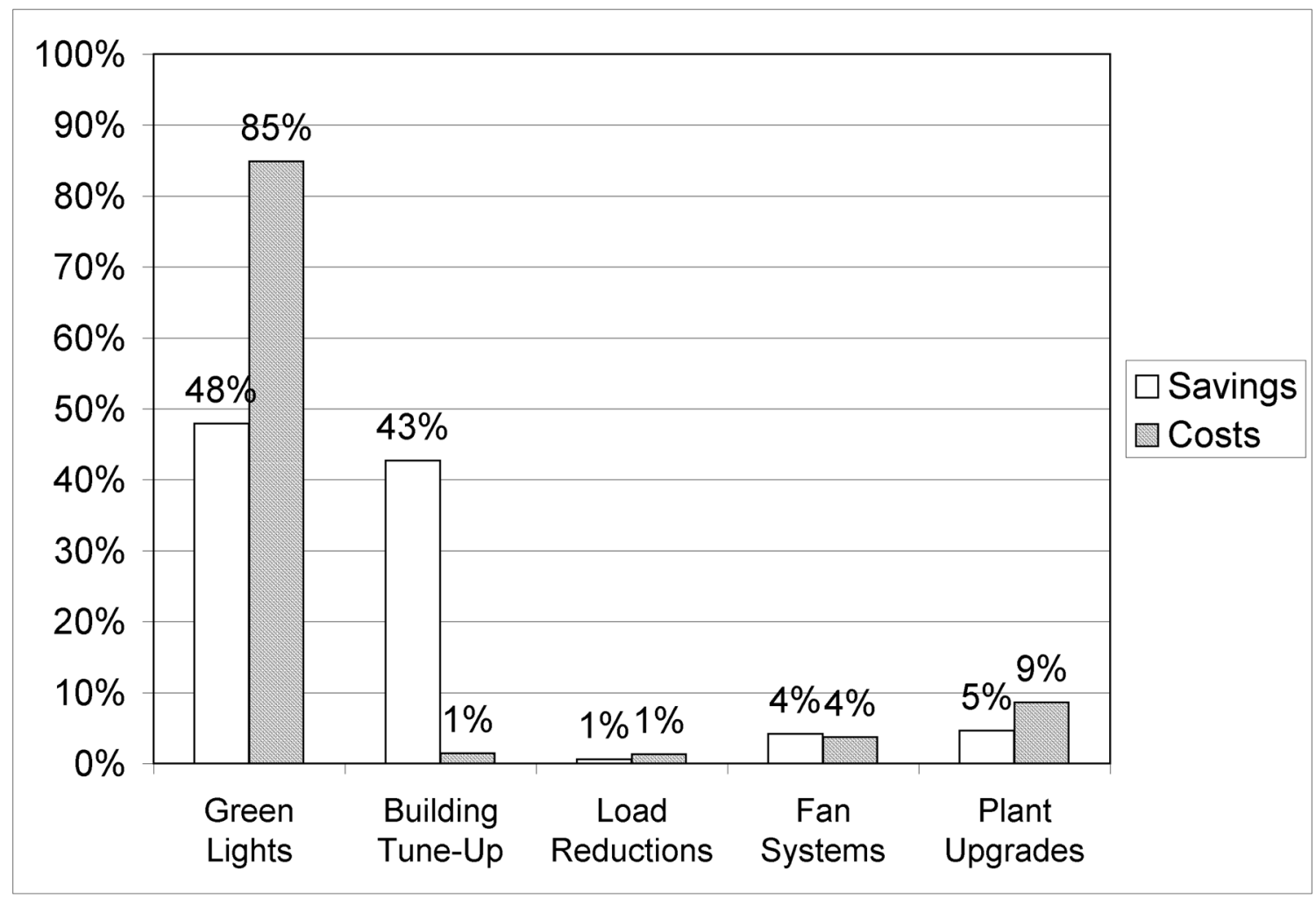

FIGURE 1: WALT DISNEY WORLD RESORT'S ENERGY STAR PROGRAM RESULTS 